\title{
Discovery of esophageal stricture following femoral neck fracture: a case of adenosquamous carcinoma of the esophagus in a young female
}

\author{
Pei Xue ${ }^{1}$, Danielle Nogoy ${ }^{1}$, Konstantinos Damiris ${ }^{1}$, Sushil Ahlawat ${ }^{* 2}$ \\ ${ }^{1}$ Department of Internal Medicine, Rutgers New Jersey Medical School, Newark, United States \\ ${ }^{2}$ Department of Gastroenterology, Rutgers new Jersey Medical School, Newark, United States
}

\author{
Received: May 30, 2021 \\ Accepted: June 29, 2021 \\ Online Published: July 22, 2021 \\ DOI: $10.5430 /$ crim.v8n1p13 \\ URL: https://doi.org/10.5430/crim.v8n1p13
}

\begin{abstract}
Adenosquamous carcinoma (ASC) of the esophagus is a rare malignancy of the esophagus with histopathologic features of both adenocarcinoma and squamous cell carcinoma. Given the rarity of this disease, there is scant literature on ASC. We report a unique case of a 29-year-old African American female with advanced ASC manifesting as a pathologic fracture. Magnetic resonance imaging (MRI) confirmed femoral fracture, and femoral biopsy demonstrated metastatic ASC. Upper endoscopy revealed a distal esophageal stricture, and histopathology confirmed ASC. To our knowledge this is the youngest case of ASC to be reported. We discuss ASC epidemiology, clinical findings, diagnosis, and current treatments.
\end{abstract}

Key Words: Adenosquamous Carcinoma, Endoscopy, Adenocarcinoma, Squamous Cell Carcinoma, Esophagus

\section{INTRODUCTION}

Adenosquamous carcinoma (ASC) of the esophagus is a rare malignancy of the esophagus associated with histologic features of both adenocarcinoma and squamous cell carcinoma. It presents most commonly in middle aged men, and comprises about $1 \%$ of all esophageal malignancies. ${ }^{[1,2]}$ In addition to the esophagus, ASC is known to affect the lung, gallbladder, pancreas, stomach, and colon. ${ }^{[2]}$ ASC of the esophagus appears to be more aggressive than either $\mathrm{AC}$ or SCC, presenting with a higher grade and stage on average. ${ }^{[1]}$ In a retrospective analysis of the SEER database, metastasis was identified in $39 \%$ of esophageal ASC cases. ${ }^{[1]}$ Commonly identified sites of metastasis are the lungs, bone, brain, and liver. ${ }^{[2]}$ We present a unique case of a young African American female who presented with advanced disease man- ifesting as a pathologic fracture. To our knowledge, this is the youngest case of adenosquamous carcinoma reported.

\section{Case PResentation}

A 29-year-old African American female presented to the emergency department with persistent right hip pain and inability to bear weight following a fall two days prior to admission. In addition, she reported non-bloody, non-bilious vomiting, odynophagia, and an unintentional weight loss of $30 \mathrm{lbs}$. She reported having undergone endoscopy two months prior at an outside hospital, which demonstrated esophagitis, moderate chronic gastritis and $\mathrm{H}$. pylori infection with no evidence of metaplasia, dysplasia or carcinoma. She subsequently received amoxicillin, clarithromycin and omeprazole for 14 days as treatment for $\mathrm{H}$. pylori infection.

*Correspondence: Sushil Ahlawat; Email: ahlawasu@ @jms.rutgers.edu; Address: 185 South Orange Ave., Newark, NJ 07103, United States. 
She endorsed active cigarette smoking (3.5 pack years), but did not report using alcohol or illicit drugs. She denied a family history of malignancies, including gastrointestinal and gynecological malignancies. Physical examination revealed right hip tenderness and swelling with a benign abdominal exam. Gynecologic examination was unremarkable, and
Pap smear was negative. Labs identified microcytic anemia with hemoglobin of $9.5 \mathrm{~g} / \mathrm{dl}, \mathrm{MCV}$ of $79.8 \mathrm{fl}$, hypokalemia of $2.5 \mathrm{meq} / \mathrm{l}$ and hypo-albuminemia of $3.2 \mathrm{~g} / \mathrm{dl}$. Computed tomography (CT) (see Figure 1A) and subsequent magnetic resonance imaging (MRI) (see Figure 1B) of her right hip are shown.

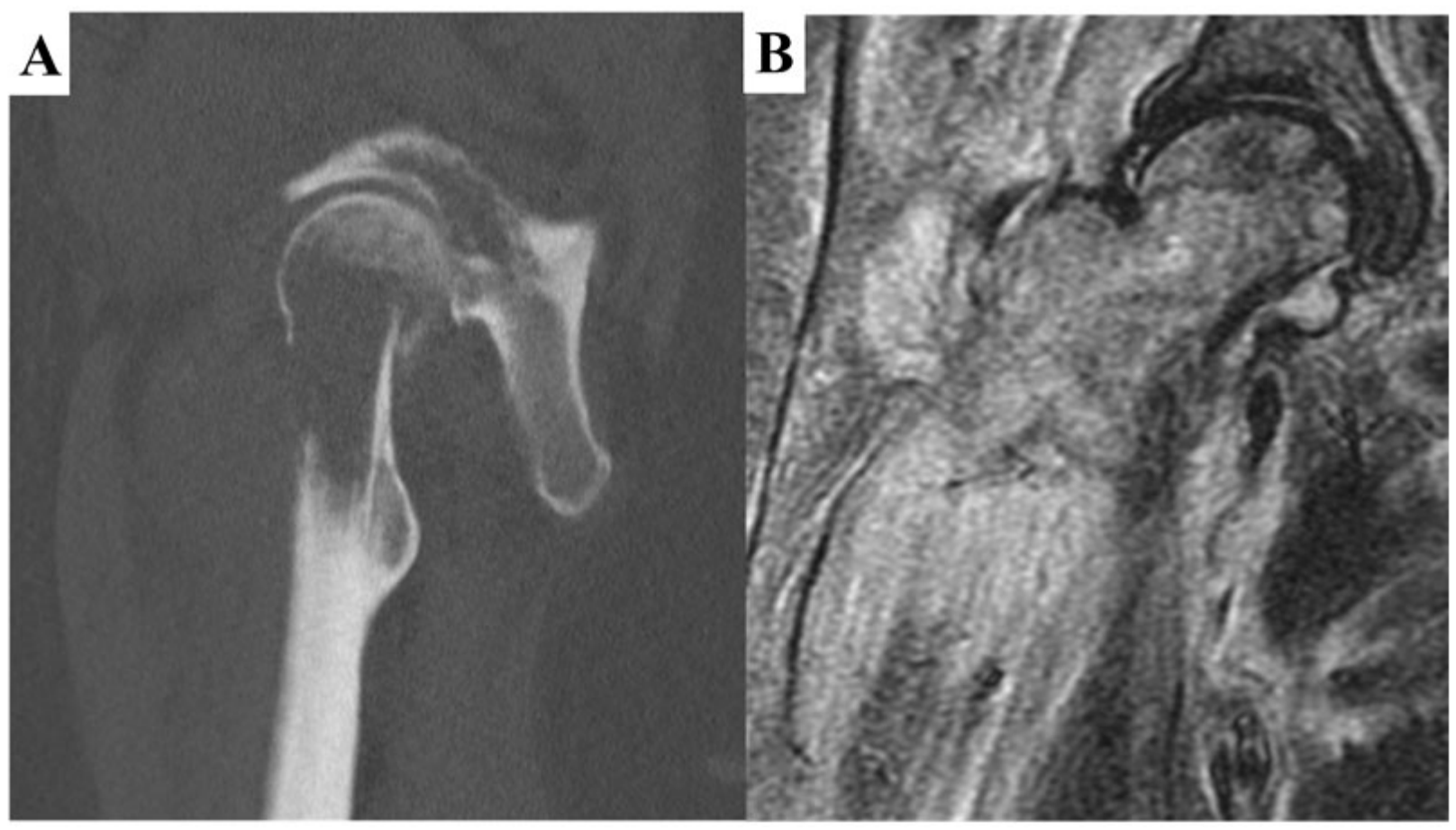

Figure 1. Coronal view of (A) CT and (B) T-2 weighted MRI scan of the right hip demonstrating a pathologic fracture with destructive lesions in the right acetabulum and right proximal femur with associated soft tissue components.

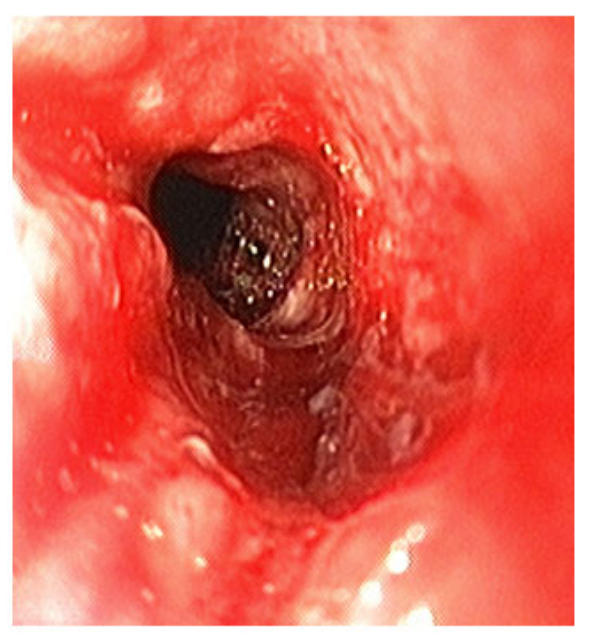

Figure 2. EGD findings showing a distal esophageal stricture
A repeat upper endoscopy was performed in order to help identify the site of primary malignancy, which revealed a 5 $\mathrm{cm}$ stricture in the distal esophagus extending to the gastroesophageal junction (see Figure 2). Surgical biopsy of the bone lesions demonstrated metastatic ASC (see Figure 3A). Biopsy of the esophageal stricture was obtained (see Figure 3B) and demonstrates poorly differentiated adenocarcinoma with both mucinous and squamous features, confirming the diagnosis of ASC. CT-scan of the chest, abdomen, and pelvis showed esophageal and gastric wall thickening, coupled with small pleural effusions, ascites, a subpleural nodule, thoracic and upper abdominal lymphadenopathy, and soft tissue thickening around the right hip and adjacent bladder wall. Unfortunately, the patient passed away from sepsis secondary to bacteremia 1 month later. 


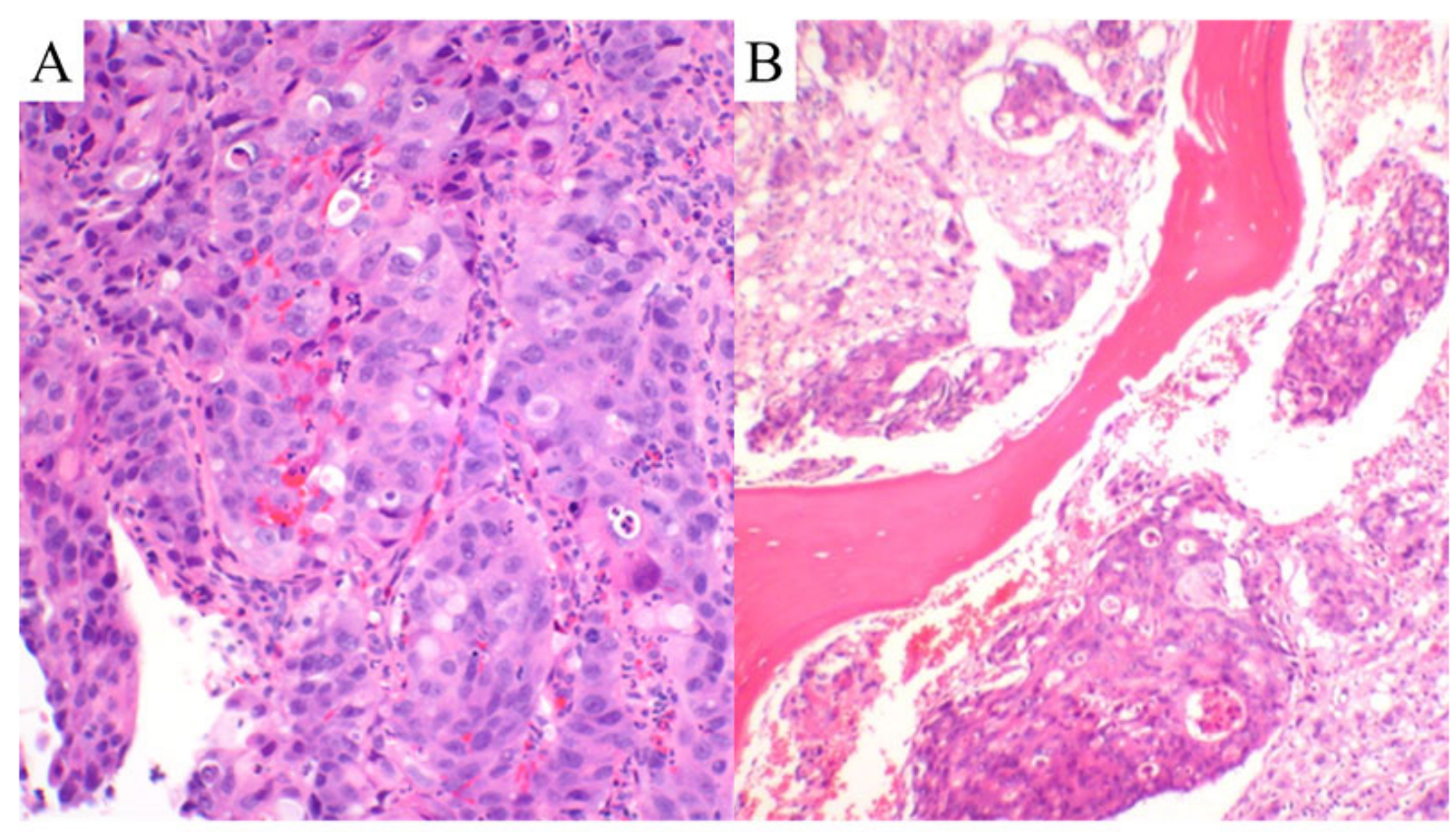

Figure 3. Biopsy of the (A) bone lesion and (B) esophageal mass showing adenosquamous carcinoma with mucinous and squamous components, suggestive of ASC

\section{DISCUSSION}

ASC is defined by the WHO 5th edition as a tumor that contains components of both SCC (squamous cell carcinoma) and AC (adenocarcinoma). ${ }^{[3]}$ The Japanese Esophageal Society refines this definition further by also requiring that each histological type must comprise at least $20 \%$ of the tumor. ${ }^{[4]}$ ASC has a low prevalence, comprising approximately $1 \%$ of all esophageal carcinomas. ${ }^{[1,2]}$

A review of the literature shows that the majority of studies on ASC were performed with small cohorts based in Asia. ${ }^{[5-7]}$ In these studies, ASC was most commonly reported in elderly patients (mean age 60-61) with a male predominance. Grossly, ASC is indistinguishable from SCC and was most often found in the middle esophagus $(50 \%) .{ }^{[5-8]}$ The symptoms that were frequently reported included dysphagia, heartburn, and weight loss. ${ }^{[5-7]}$ In terms of survival, ASC has a worse overall survival when compared to $\mathrm{AC}$, and is more comparable with SCC. ${ }^{[1]}$ ASC appears to be an aggressive tumor that typically presents at a higher grade and more progressed stage when compared to AC or SCC alone..$^{[1,2]}$

Histological diagnosis of ASC can be challenging and as a result it is often misdiagnosed. ${ }^{[5]}$ The SCC component may present with intercellular bridges, keratin pearls, and individual cell keratinization, while the AC component presents with tubular or glandular structures. ${ }^{[8]}$ Difficulty in diagnosis arises from incomplete sampling, as squamous components are typically more superficial, while AC components are deeper within the esophageal wall. ${ }^{[8]}$ Furthermore, ASC is not to be confused with mucoepidermoid carcinoma of the esophagus (MECE), a similar tumor that also presents with mixed SCC and AC components. MECE is characterized by mucus-containing adenocarcinoma cells found within nests of SCC, and is distinguished by a clear transitional section between SCC and AC histology with intermediate cells. $^{[4,8-10]}$

The treatment of ASC is not well defined by the literature. As with other esophageal malignancies, surgery is typically used for locally invasive disease while nonsurgical options (i.e. chemotherapy) can be used for more advanced disease. Since ASC has features of both AC and SCC of the esophagus, it is unclear which treatment option is more effective. A recent study suggests that in lymph node negative (N0) disease, surgical treatment is sufficient, but in node positive (N1-N3) disease, preoperative chemoradiation with resection has improved outcomes compared with resection or chemoradiation alone. ${ }^{[11]}$

To our knowledge, no cases of an African American female younger than 50 years old with adenosquamous carcinoma of the esophagus have been reported in the literature. Our case is unique in that a young patient presented with advanced disease (AJCC stage IV, T4N3M1G3) and a fracture secondary to metastatic disease to the hip.

\section{CONFlicts of Interest Disclosure}

The authors have declared no conflicts of interest. 


\section{REFERENCES}

[1] Yendamuri S, Malhotra U, Hennon M, et al. Clinical characteristics of adenosquamous esophageal carcinoma. J Gastrointest Oncol. 2017 8(1): 89-95. PMid:28280613. https : //doi .org/10.21037/jgo .2016 .12 .03

[2] Evans M, Liu Y, Chen C, et al. Adenosquamous Carcinoma of the Esophagus: An NCDB-Based Investigation on Comparative Features and Overall Survival in a Rare Tumor. Oncology. 2017; 93(5): 336342. PMid:28848104. https ://doi.org/10.1159/000466699

[3] Sun YH, Lin SW, Chen CH, et al. Adenosquamous Carcinoma of the Esophagus and Esophagogastric Junction: Clinical Manifestations and Treatment Outcomes. J Gastrointest Surg. 2015 Jul; 19(7): 1216-22. PMid:25967141. https ://doi.org/10.1007/s11605 $-015-2852-\mathrm{x}$

[4] Japan Esophageal Society. Japanese Classification of Esophageal Cancer, 11th Edition: part II and III. Esophagus. 2017; 14(1): 37 65. PMid:28111536. https://doi.org/10.1007/s10388-016 $-0556-2$

[5] Zhang HD, Chen CG, Gao YY, et al. Primary esophageal adenosquamous carcinoma: a retrospective analysis of 24 cases. Dis Esophagus. 2014 Nov-Dec; 27(8): 783-9. PMid:24127755.https://doi.org/10.1007/s12072-020-10077https://doi.org/10.1111/dote.12153
[6] Yachida S, Nakanishi Y, Shimoda T, et al. Adenosquamous carcinoma of the esophagus. Clinicopathologic study of 18 cases. Oncology. 2004; 66(3): 218-225. PMid:15218313. https://doi.org/ $10.1159 / 000077998$

[7] Ni PZ, Yang YS, Hu WP, et al. Primary adenosquamous carcinoma of the esophagus: an analysis of 39 cases. J Thorac Dis. 2016; 8(10): 2689-2696. PMid:27867543. https://doi.org/10.21037/jtd .2016 .09 .59

[8] Chen SB, Weng HR, Wang G, et al. Primary adenosquamous carcinoma of the esophagus. World J Gastroenterol. 2013; 19(45): 8382-8390. PMid:24363531. https://doi.org/10.3748/wjg. v19.i45.8382

[9] Schizas D, Kapsampelis P, Mylonas KS. Adenosquamous carcinoma of the esophagus: a literature review. J Transl Int Med. 2018 Jun; 6(2): 70-73. PMid:29984200. https://doi.org/10.2478/jtim $-2018-0014$

[10] Huang Q, Shi J, Sun Q, et al. Distal esophageal carcinomas in Chinese patients vary widely in histopathology, but adenocarcinomas remain rare. Hum Pathol. 2012; 43(12): 2138-2148. PMid:22658274. https ://doi.org/10.1016/j.humpath.2012.02.018

[11] Gamboa AC, Meyer BI, Switchenko JM, et al. Should adenosquamous esophageal cancer be treated like adenocarcinoma or squamous cell carcinoma?. J Surg Oncol. 2020; 122(3): 412-421. PMid:32462769. https ://doi.org/10.1002/jso. 25990 